\title{
Isolation and Identification of a Novel Impurity of Erythromycin A 9-0xime Desosaminehydrazinium Salt
}

\author{
Casey Chun Zhou, Xiaomei Huang, Kelley L. Ford, L. Steven Hollis
}

Received: April 8, 2005 / Accepted: August 12, 2005

(C) Japan Antibiotics Research Association

\begin{abstract}
In the manufacturing process for Biaxin ${ }^{\circledR}$ (clarithromycin), erythromycin-A oxime, an intermediate, is obtained in high yield, when erythromycin-A is treated with hydroxylamine/isopropyl alcohol in the presence of acetic acid. An unusual impurity, the desosamine hydrazinium salt, is generated in this step of the synthetic pathway, and has been isolated and characterized by using one and two-dimensional NMR spectroscopy in conjunction with MS and EDS.
\end{abstract}

Keywords erythromycin A 9-oxime, hydrazinium salt, NMR

Erythromycin is a well established macrolide antibiotic that is used to treat a wide variety of bacterial infections in man $[1,2]$. Erythromycin's instability under the acidic conditions that are present in the stomach can give inactive by-products resulting in low bioavailability [3, 4]. As a result, a number of semi-synthetic erythromycin derivatives have been developed to improve acid stability in the gastrointestinal track [4 8]. Erythromycin-A 9-oxime is an important intermediate in the synthesis of $\operatorname{Biaxin}^{\circledR}$ (clarithromycin), a second-generation macrolide antibiotic, which has proven to be a clinical and commercial success due to its improved antibacterial activity and pharmacokinetic profile [7, 9]. Erythromycin-A oxime is obtained in high yield when erythromycin-A is treated with hydroxylamine/isopropyl alcohol in the presence of acetic acid, as shown in Scheme 1 [10]. A new impurity has been identified in this step of the synthetic pathway, and in this report we would like to present information on the isolation and characterization of this compound and discuss the possible mechanism by which it is formed.

\section{Formation and isolation of the impurity}

Erythromycin A 9-oxime has been prepared from the reaction of erythromycin-A with hydroxylamine in methanol $[11,12]$. Since this reaction was found to produce a number of degradation impurities, an improved procedure was developed to prepare the 9-oxime. In the improved process, erythromycin-A is treated with hydroxylamine and acetic acid in isopropyl alcohol [10]. This modification provides a better impurity profile, however it also leads to a new impurity that was not previously observed in this step of the reaction sequence. The concentration of this new impurity was found to increase with prolonged reaction times and/or with raised reaction temperatures. When a reaction mixture of erythromycin-A, acetic acid and hydroxylamine was heated to $58^{\circ} \mathrm{C}$ in isopropyl alcohol for 72 hours (or at $70^{\circ} \mathrm{C}$ for 24 hours), the new impurity was observed by HPLC at a concentration of 4.7 (or 6.0) areapercent, respectively.

Two different methods were used to isolate the impurity from this reaction. In the first method, isopropyl acetate and aqueous sodium hydroxide solution $(6 \mathrm{M})$ were added to the reaction mixture after the reaction was complete. A solid precipitate was collected from the solution by filtration and was found to contain $60 \%$ of the unknown impurity by HPLC. The isolated impurity was recrystallized twice from methanol and once from a mixture of methanol and ethyl acetate. The recrystallized material was found to be $93.6 \%$ pure by HPLC. NMR, MS and EDS (energy dispersive X-
C. C. Zhou (Corresponding author), Xiaomei Huang, Kelley L. Ford, L. Steven Hollis: D-R418, Structural Chemistry, Global Pharmaceutical Research and Development, Abbott Laboratories,
1401 Sheridan Road, North Chicago, IL 60064-4000 USA, E-mail: chun.zhou@abbott.com 


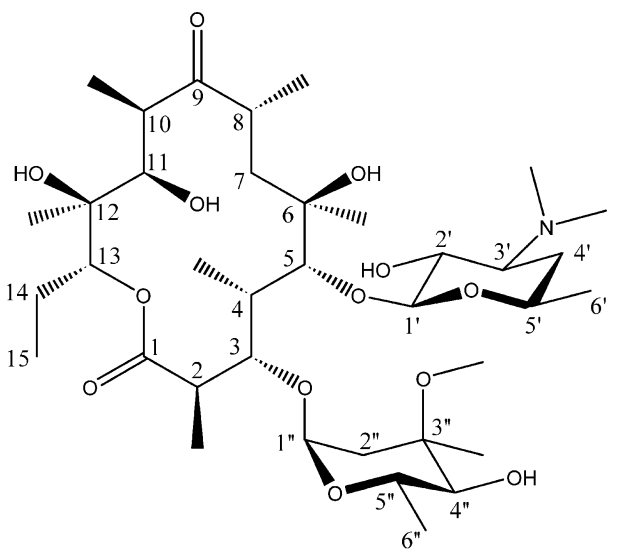

Erythromycin A

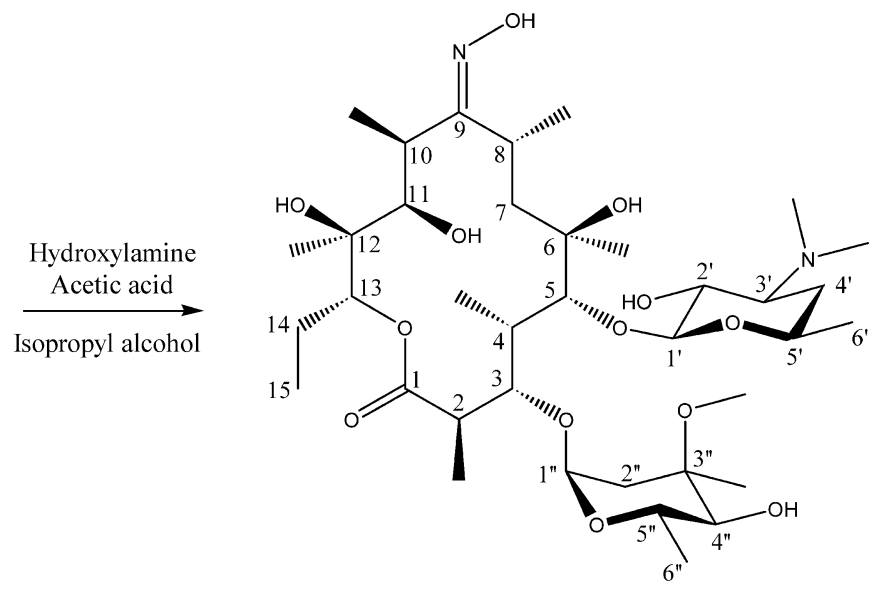

Erythromycin A Oxime

Scheme 1.

ray spectroscopy) were used to determine the structure of this impurity, isolated as the acetate salt (compound $\mathbf{1}$, see Fig. 1).

A second method was used to isolate the chloride salt of the impurity. In this procedure, isopropyl acetate and aqueous sodium hydroxide were added to the solution after the reaction was complete and the aqueous layer was separated and treated with $20 \%$ aqueous sodium chloride. After this mixture was agitated for a few minutes, a white solid was filtered from the solution, and this material exhibited the same retention time as compound $\mathbf{1}$, by HPLC (with $80 \%$ purity). The isolated material was then recrystallized from methanol, yielding compound $\mathbf{2}$ in $90 \%$ purity. This compound was identified as the chloride salt (2) of the impurity (see Fig. 1) by NMR, MS and EDS.

\section{Identification of the impurity}

Both compounds 1 and $\mathbf{2}$ were freely soluble in DMSO- $d_{6}$ and therefore NMR spectra were acquired in this solvent. The ${ }^{1} \mathrm{H}$ and ${ }^{13} \mathrm{C}$ chemical shifts for both compounds were assigned with the aid of standard g-DQCOSY, g-HSQC, and $\mathrm{g}$-HMBC experiments.

The proton and carbon chemical shifts for compound $\mathbf{1}$ and $\mathbf{2}$ could be assigned from these studies, as shown in the assigned g-HSQC spectra (Fig. 2B and E) and Table 1 for compound 2. Cross-peaks for the methine protons at positions 8 and 10 did not show reasonable intensity in the g-HSQC spectra for both compounds. However, these signals were clearly visible when the NMR data was acquired in pyridine- $d_{5}$ (see Table 1). Both compounds showed the similar correlations between the $-\mathrm{NH}_{2}, 3^{\prime}-$ $\mathrm{N}\left(\mathrm{CH}_{3}\right)_{2}$ and $3^{\prime} \mathrm{CH}$ groups in the g-HMBC spectra (Fig. $2 \mathrm{C}$ and $\mathrm{F})$. The carbon chemical shifts for the $3^{\prime}-\mathrm{N}\left(\mathrm{CH}_{3}\right)_{2}$ group in the desosamine sugar are normally at about

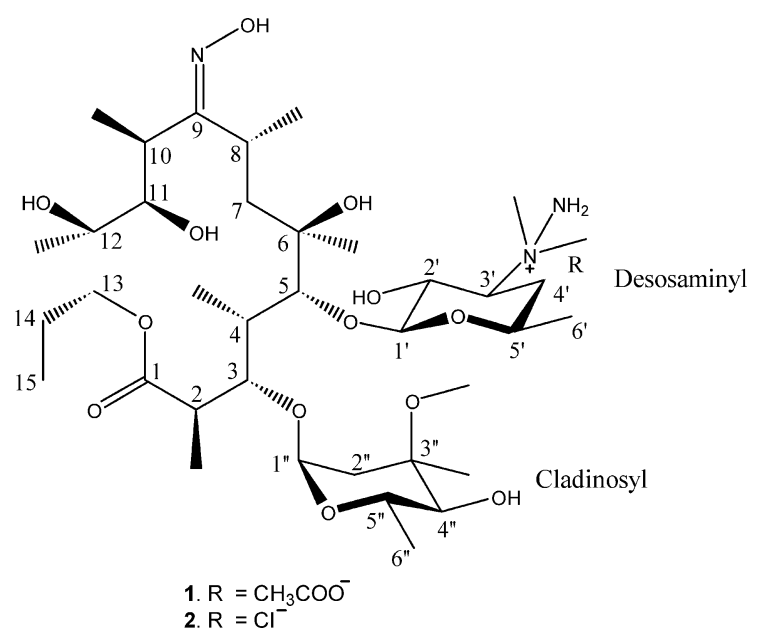

Fig. 1 The structure of the impurity that was isolated as two different salt forms.

$40 \mathrm{ppm}$ in erythromycin. In contrast, the carbon chemical shifts for the $3^{\prime}-\mathrm{N}\left(\mathrm{CH}_{3}\right)_{2}$ group in the impurity are in the $50 \sim 60 \mathrm{ppm}$ range, which is even further downfield than the $-\mathrm{OCH}_{3}(\sim 49 \mathrm{ppm})$ group at position $3^{\prime \prime}$. This fact suggests that the nitrogen on the desosamine ring is charged, as expected in the case of a hydrazinium salt of a tertiary amine. Exact-mass MS measurements for both compounds indicate a MW of $764.4918(\mathrm{~m} / \mathrm{z})$, which is consistent with the proposed molecular formula $\mathrm{C}_{37} \mathrm{H}_{70} \mathrm{~N}_{3} \mathrm{O}_{13}{ }^{+}$.

In comparing the NMR spectra of compound $\mathbf{1}$ and $\mathbf{2}$, some chemical shift differences can be found in the region of the desosamine sugar at the $2^{\prime}, 3^{\prime}$ and $3^{\prime}-\mathrm{N}\left(\mathrm{CH}_{3}\right)_{2}$ positions. In compound $\mathbf{1}$, an acetate signal is also observed in the proton spectrum at a level that corresponds to a $1: 1$ mole-ratio of compound $\mathbf{1}$ to acetate, and EDS confirms that no other heteroatoms are present except oxygen. In the 
Table $1{ }^{1} \mathrm{H}$ and ${ }^{13} \mathrm{C}$ assignments of compound $\mathbf{2}$ in DMSO- $d_{6}$ and pyridine- $d_{5}$

\begin{tabular}{|c|c|c|c|c|c|}
\hline \multirow{2}{*}{ Position } & \multirow{2}{*}{ Group } & \multicolumn{2}{|c|}{ DMSO- $d_{6}$} & \multicolumn{2}{|c|}{ Pyridine- $d_{5}$} \\
\hline & & ${ }^{1} \mathrm{H}(\mathrm{ppm})^{\mathrm{a}}$ & $\left.{ }^{13} \mathrm{C}(\mathrm{ppm})\right)^{\mathrm{b}}$ & ${ }^{1} \mathrm{H}(\mathrm{ppm})^{\mathrm{c}}$ & ${ }^{13} \mathrm{C}(\mathrm{ppm})^{\mathrm{d}}$ \\
\hline 1 & $C=O$ & - & 174.6 & - & 175.7 \\
\hline 2 & $\mathrm{CH}$ & 2.79 & 44.2 & 3.18 & 45.1 \\
\hline 2-Me & $\mathrm{CH}_{3}$ & 1.10 & 16.0 & 1.33 & 16.3 \\
\hline 3 & $\mathrm{CH}$ & 3.83 & 78.1 & 4.49 & 79.5 \\
\hline 4 & $\mathrm{CH}$ & 1.94 & 38.4 & 2.51 & 39.3 \\
\hline 4-Me & $\mathrm{CH}_{3}$ & 1.00 & 9.3 & 1.55 & 9.8 \\
\hline 5 & $\mathrm{CH}$ & 3.47 & 82.9 & 4.07 & 84.5 \\
\hline 6 & $C=O$ & - & 74.1 & - & 74.7 \\
\hline 6-Me & $\mathrm{CH}_{3}$ & 1.32 & 26.5 & 1.96 & 27.1 \\
\hline 7 & $\mathrm{CH}_{2}$ & 1.49 & 37.3 & $1.87,1.75$ & 38.2 \\
\hline 8 & $\mathrm{CH}^{2}$ & $3.58^{*}$ & 25.0 & 4.28 & 25.7 \\
\hline 8-Me & $\mathrm{CH}_{3}$ & 0.99 & 18.7 & 1.10 & 19.0 \\
\hline 9 & $\mathrm{C}=\mathrm{NOH}$ & - & 168.9 & - & 170.1 \\
\hline 10 & $\mathrm{CH}$ & 2.64 & $32.7^{*}$ & 2.94 & $33.2^{*}$ \\
\hline 10-Me & $\mathrm{CH}_{3}$ & 1.08 & 14.6 & 1.48 & 15.0 \\
\hline 11 & $\mathrm{CH}$ & 3.53 & 70.3 & 4.32 & 71.2 \\
\hline 12 & $C=0$ & - & 74.1 & - & 74.6 \\
\hline 12-Me & $\mathrm{CH}_{3}$ & 1.01 & 17.0 & 1.36 & 17.0 \\
\hline 13 & $\mathrm{CH}$ & 5.13 & 76.0 & 5.70 & 77.0 \\
\hline 14 & $\mathrm{CH}_{2}$ & $1.82,1.37$ & 20.9 & $2.17,1.64$ & 21.5 \\
\hline 15 & $\mathrm{CH}_{3}$ & 0.74 & 10.6 & 0.87 & 10.7 \\
\hline $1^{\prime}$ & $\mathrm{CH}^{3}$ & 4.50 & 100.7 & 5.15 & 101.9 \\
\hline $2^{\prime}$ & $\mathrm{CH}$ & 3.58 & 70.5 & 4.24 & 72.2 \\
\hline $3^{\prime}$ & $+\mathrm{NCH}$ & 3.58 & 75.4 & 4.56 & 75.7 \\
\hline 3'-NMe & $+\mathrm{N}\left(\mathrm{CH}_{3}\right)_{2}$ & $3.35,3.22$ & $55.2,53.2$ & $3.94,3.67$ & $54.8,53.1$ \\
\hline $4^{\prime}$ & $\mathrm{CH}_{2}$ & $2.14,1.49$ & 32.7 & $2.44,1.68$ & 34.0 \\
\hline $5^{\prime}$ & $\mathrm{CH}$ & 3.75 & 65.5 & 4.30 & 66.4 \\
\hline $6^{\prime}$ & $\mathrm{CH}_{3}$ & 1.13 & 20.9 & 1.29 & 21.2 \\
\hline $1^{\prime \prime}$ & $\mathrm{CH}$ & 4.75 & 95.4 & 5.09 & 96.4 \\
\hline $2^{\prime \prime}$ & $\mathrm{CH}_{2}$ & $2.27,1.53$ & 34.8 & $2.38,1.46$ & 35.3 \\
\hline $3^{\prime \prime}$ & $C=O$ & - & 72.6 & - & 73.3 \\
\hline 3"-Me & $\mathrm{CH}_{3}$ & 1.14 & 21.1 & 1.36 & 21.3 \\
\hline 3"-OMe & $\mathrm{CH}_{3}$ & 3.23 & 48.9 & 3.60 & 49.5 \\
\hline $4^{\prime \prime}$ & $\mathrm{CH}$ & 2.92 & 77.2 & 3.24 & 78.5 \\
\hline $5^{\prime \prime}$ & $\mathrm{CH}$ & 3.97 & 64.9 & 4.49 & 66.0 \\
\hline $6^{\prime \prime}$ & $\mathrm{CH}_{3}$ & 1.16 & 18.5 & 1.50 & 18.9 \\
\hline 9 & $\mathrm{~N}-\mathrm{OH}$ & 10.70 & - & 12.86 & - \\
\hline 11 & $\mathrm{OH}$ & 4.12 & - & 4.34 & - \\
\hline $2^{\prime}$ & $\mathrm{OH}$ & 6.32 & - & 8.33 & - \\
\hline $3^{\prime}$ & $\mathrm{N}-\mathrm{NH}_{2}$ & 6.36 & - & 7.88 & - \\
\hline $4^{\prime \prime}$ & $\mathrm{OH}$ & 4.43 & - & 5.60 & - \\
\hline
\end{tabular}

${ }^{a}$ The ${ }^{1} \mathrm{H}$ chemical shifts are referenced relative to the residual signal from DMSO- $d_{6}$ assigned as $2.50 \mathrm{ppm}$.

${ }^{\mathrm{b}}$ The ${ }^{13} \mathrm{C}$ chemical shifts are referenced to DMSO- $d_{6}$ assigned as $39.5 \mathrm{ppm}$.

${ }^{\mathrm{c}}$ The ${ }^{1} \mathrm{H}$ chemical shifts are referenced relative to the middle residual signal from pyridine- $d_{5}$ assigned as $7.55 \mathrm{ppm}$.

${ }^{d}$ The ${ }^{13} \mathrm{C}$ chemical shifts are referenced to the middle signal from pyridine- $d_{5}$ assigned as $135.5 \mathrm{ppm}$.

* Not accurate due to broad or overlapping signals. 

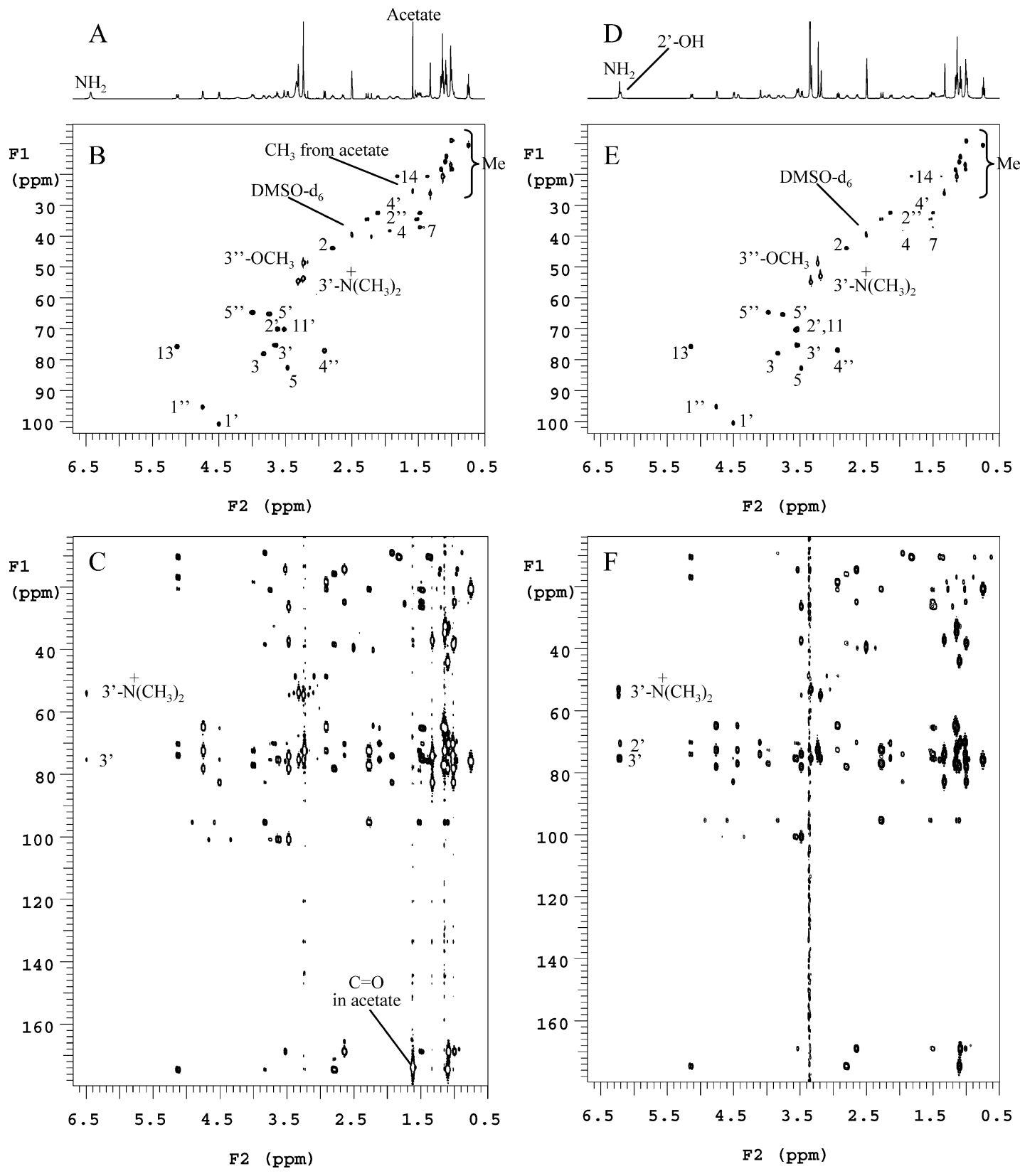

Fig. 2 NMR spectra in DMSO- $d_{6}$ of compound 1 (A) ${ }^{1} \mathrm{H}$, (B) g-HSOC, (C) g-HMBC and compound 2 (D) ${ }^{1} H$, (E) g-HSOC, and (F) g-HMBC. Most of peaks in g-HSQC are labeled except for the methyl groups, which are too crowded to display the labels (see Table 1 for the assignments) and some selected peaks of interest are labeled in the ${ }^{1} \mathrm{H}$ and g-HMBC spectra.

case of compound $\mathbf{2}$, the proton and carbon signals of the acetate anion were not observed in the spectra, and EDS indicated that chloride was present in the sample. Therefore, we have identified compound $\mathbf{2}$ as the chloride salt of the parent compound shown in Fig. 1. Further experiments proved that acetate can be replaced by the chloride anion when the compound is placed in a chloride solution during the purification process.

In DMSO- $d_{6}$ solutions, the oxime group in both compound $\mathbf{1}$ and $\mathbf{2}$ was determined to be in the $E$ configuration (where the oxime's hydroxyl group is syn to C8). The identifcation of the $E$ configuration was supported by the downfield proton shift of $\mathrm{H} 8(\sim 3.6 \mathrm{ppm})$, the downfield carbon shift of $10-\mathrm{CH}_{3}(\sim 15 \mathrm{ppm})$, the upfield proton shift of $8-\mathrm{CH}_{3}(\sim 1.0 \mathrm{ppm})$, and the upfield carbon shift of $\mathrm{C} 8 \quad(\sim 25 \mathrm{ppm})$, resulting from shielding/ deshielding effects based on steric interactions with the cis-hydroxyl group of the oxime. The assignments 


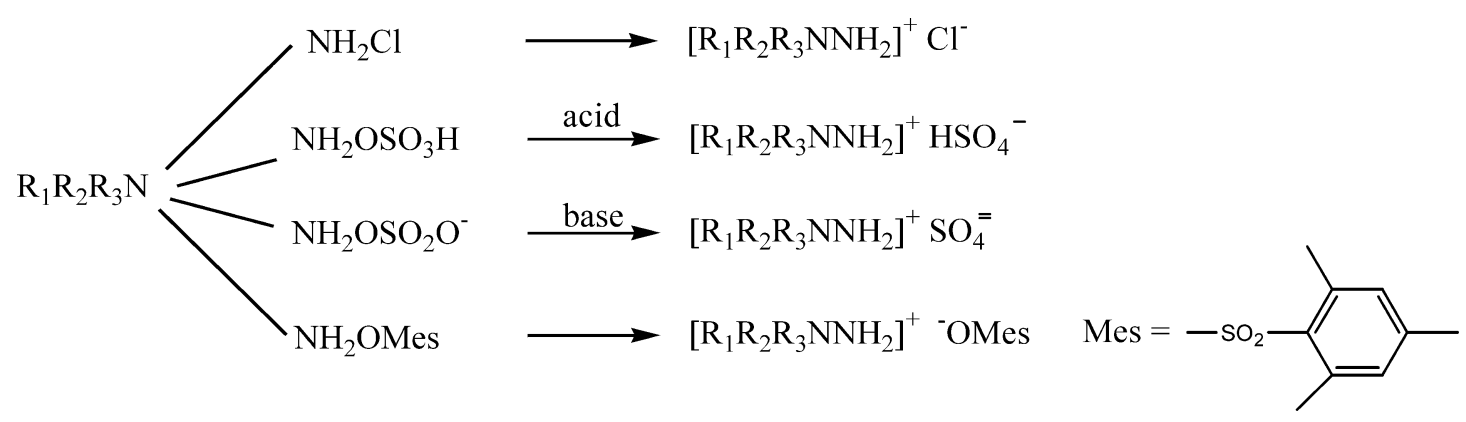

\section{Scheme 2.}

are consistent with the previous reports on oxime conformations $[5,13,14]$.

\section{Possible Reaction Mechanism}

Several methods have been reported for the preparation of 1,1,1-trisubstituted hydrazinium salts of tertiary amines [15 17]. One well known method is the reaction of chloramine with tertiary amines which provides the corresponding 1,1,1-trisubstituted hydrazinium chlorides in good yield [15]. It is believed that the mechanism of this reaction involves an acid-base interaction, in the Lewis sense, with chloramine being the electrophilic reagent. This reaction can be further modified with other reagents like hydroxylamine- $O$-sulfonic acid [16] and $\mathrm{NH}_{2} \mathrm{OMes}$ [17], as shown in Scheme 2. All the $\mathrm{NH}_{2} \mathrm{X}$ compounds in this scheme, where $\mathrm{X}$ represents an electronegative group, are efficient amination reagents. In these cases, $\mathrm{X}$ is also a very good leaving group. The reaction of $\mathrm{NH}_{2} \mathrm{OMes}$ with tropinone, which contains both a tertiary amine and a ketone group, gives rise to the $N$-amine salt only. It appears that, in this case, $N$-amination proceeds faster than oxime formation.

In our case, where $\mathrm{NH}_{2} \mathrm{OH}$ was used as an amination reagent, the hydroxyl group is not a good leaving group and therefore the formation of 1,1,1-trisubstituted hydrazinium is not as efficient as it would be with the other reagents mentioned above. In fact, in this reaction, the oximation proceeds much faster than the $N$-amination reaction. That explains why the impurity is observed only in the presence of excess amounts of $\mathrm{NH}_{2} \mathrm{OH}$, or with prolonged reaction times and high reaction temperatures. Also trace amounts of $\mathrm{NH}_{2} \mathrm{OAc}$ could be formed under the reaction conditions and this might be the active reagent for the formation of this hydrazinium.

Acknowledgements The authors would like to thank Dr. Richard Burton for his MS support, Dr. Robert Biddle for his EDS measurements, and Dr. Yugui Gu, Dr. Xiaolin Zhang, Mike Cirovic, Steve Cepa, and Dr. Paul West for their useful discussions.

\section{References}

1. Mcguire JM, Bunch RL, Anderson RC, Boaz HE, Flynn EH, Powell HM, Smith JW. "Ilotycin," a new antibiotic. Antibiot Chemother 2: 281-283 (1952)

2. Washington JA, Wilson WR. Erythromycin: A microbial and clinical perspective after 30 years of clinical use. Mayo Clin Proc 60: 189-203 \& 271-278 (1985)

3. Kurath P, Jones RS, Egan RS, Perun TJ. Acid degradation of erythromycin A and erythromycin B. Experientia 27: 362 (1971)

4. Atkins PJ, Herbert TO, Jones NB. Kinetic studies on the decomposition of erythromycin $\mathrm{A}$ in aqueous acidic and neutral buffers. Int J Pharm 30: 199-207 (1986)

5. Gasc JC, Gouin D'ambrieres S, Lutz A, Chantot JF. New ether oxime of erythromycin A a structure activity relationship study. J Antibiot 44: 313-330 (1991)

6. Chantot JF, Bryskier A, Gasc JC. Antibacterial activity of roxithromycin: a laboratory evaluation. J Antibiot 39: 660-668 (1986)

7. Morimoto S, Takahashi Y, Watanabe Y, Omura S. Chemical modifications of erythromycins I. Synthesis and antibacterial activity of 6-O-methylerythromycin A. J Antibiot 37: 187-189 (1984)

8. Retsema JA, Girard AE, Schekly W, Manousos M, Anderson MR, Bright GM, Borovoy RJ, Brennan LA, Mason R. Spectrum and mode of action of azithromycin (CP-62,993), a new 15 membered-ring macrolide with improved potency against gram negative organisms. Antimicrob Agents Chemother 31: 1939-1947 (1987)

9. Chu D. Recent developments in 14- and 15-membered macrolides. Exp Opin Invest Drugs 4: 65-94 (1995)

10. Chang Sou-Jen. Process for preparing erythromycin A oxime. WO 97/38000, PCT/US97/03177 (1997)

11. Massey EH, Kitchell B, Martin LD, Gerzon K, Murphy HW. Erythromycylamine. Tetrahedron Letters 2: 157-160 (1970)

12. Takehiro Amano U, Masami Goi S, Kazuto Sekiuchi T, Tomomichi Yoschida MH. Process for preparing erythromycin A oxime or a salt thereof. US 5274085 A 
(1993)

13. Egan RS, Freiberg LA, Washburn WH. Configuration of 9imino derivatives of erythromycin. J Org Chem 39: 2492-2494 (1974)

14. McGill JM, Johnson R. Structural and conformational analysis of (E)-erythromycin A oxime. Magn Reson Chem 31: 273-277 (1993)

15. Omietanski GM, Sisler HH. The reaction of chloramines with tertiary amines. 1,1,1-Trisubstituted hydrazinium salts.
J Am Chem Soc 78: 1211-1213 (1956)

16. Sisler HH, Bafford RA, Omietanski GM, Rudner B, Drago RJ. Amination of tertiary amines by hydroxylamine-Osulfonic acid. J Org Chem 24: 859-861 (1959)

17. Tamura Y, Minamikawa J, Kita Y, Kim JH, Ikeda M. Namination of tertiary amines: a novel method for 1,1,1trisubstituted hydrazinium salts. Tetrahedron 29: 1063-1068 (1973) 